\title{
O SIMBOLISMO PENAL E A DESLEGITIMAÇÃO DO PODER PUNITIVO NA SOCIEDADE DE RISCO: CONSEQUÊNCIAS E IMPRECISÕES
}

\section{THE CRIMINAL SYMBOLISM AND THE NO-LEGITIMIZATION OF PUNITIVE POWER IN RISK SOCIETY: CONSEQUENCES AND INACCURACIES}

\author{
${ }^{1}$ Kelvia de Oliveira Toledo \\ ${ }^{2}$ Claudio Abel Franco de Assis
}

\section{RESUMO}

O presente artigo tem por objetivo abordar o Direito Penal Simbólico, sobretudo servindo-se das contribuições da teoria deslegitimante não-abolicionista do poder punitivo, na forma do realismo marginal de Eugênio Raul Zaffaroni, tendo como aporte teórico toda a historicidade de expansão do Direito Penal, pautada na sua crescente funcionalização e na profunda e grave crise de legitimidade que o mesmo tem sofrido. Ademais, busca-se compreender a aplicação da Justiça Penal em um Estado Democrático de Direito e os seus possíveis paradoxos na sociedade contemporânea, tendo em vista a crescente expansão da tutela penal, a sua utilização simbólica e, bem como, os desafios do Direito Penal moderno, que deve servir de instrumento garantista dos princípios fundamentais insculpidos na Carta Maior. Assim sendo, o artigo procura destrinchar tais questões a partir de experimentações teóricas que acenam para a discussão dessa crucial temática do Direito Penal Simbólico dos tempos atuais.

Palavras-chave: Direito penal simbólico, Sociedade de risco, Crise de legitimidade do poder punitivo, Estado democrático de direito, Política criminal, Sistema penal

\begin{abstract}
This papers presents the discuss of the Symbolic Criminal Law, based on no-legitimization theory such as the marginal realism of Eugenio Raul Zaffaroni, with the theoretical support all the historicity of expansion of Criminal Law and its growing functionalization and legitimacy or no-legitimacy crisis that it has experienced. Therefore, we seek to understand the application of Criminal Justice in Democratic rule-of-law State and its possible paradoxes in contemporary society, like the increasing expansion of penal law, its symbolic use and the challenges of the Criminal Law modern, which should work as a instrument of the valuable principles fixed in the Constitution. Accordingly this, the article tries to develop these issues from theoretical discussions of Symbolic Criminal Law in the the modern times.
\end{abstract}

Keywords: Symbolic criminal law, Risk society, No- legitimization of punitive power, Democratic rule-of-law state, Criminal policy, Criminal system

\footnotetext{
${ }^{1}$ Mestrando em Direito na Universidade Católica de Petrópolis - UCP, Petrópolis - RJ (Brasil). Professora da Universidade Federal de Juiz de Fora - UFJF, Juiz de Fora - MG (Brasil). E-mail: kelvia_toledo@ hotmail.com

2 Mestre em Direito pela Universidade Católica de Petrópolis - UCP, Petrópolis - RJ (Brasil). Professor da Universidade Federal de Juiz de Fora- UFJF, Juiz de Fora - MG (Brasil). E-mail: claudio.franco@ufjf.edu.br
} 


\section{INTRODUÇÃO}

O presente artigo visa abordar, sintética e analiticamente, a partir de reflexões embasadas na doutrina penalista, as principais características do Direito Penal Simbólico, que é uma das faces em que o Direito Penal atual mais se revela, e, bem como, a sua cotidiana aplicação, mesmo que ilegítima, superficial e ineficaz no Estado moderno.

Em um primeiro momento, será abordado como a expansão do Direito Penal contribuiu para a crescente funcionalização deste ramo, lastreado na sociedade de risco da contemporaneidade. Em tal concepção, com o processo de globalização, novas necessidades e novos pensamentos se fizeram necessários enquanto mecanismos de tutela de relações e de pacificação social, não podendo, por conseguinte, o Direito Penal se posicionar alheio às mudanças que se operaram no âmago da sociedade. Isto posto, o mesmo acaba inserido nessa fase de múltiplas interconexões causais e, consequentemente, de incertezas, passando a ser demandado a agir com frequência cada vez maior. Dessa sorte, o Estado, por meio de intensa legiferação, ainda que em detrimento de valiosos princípios constitucionais, utiliza esse Direito Penal para intervir na sociedade, mesmo que simbolicamente, pautado na firme convicção de estar esmorecendo o fervor social.

Aliado a essa referida evolução do mundo globalizado, o generalizado clima de ansiedade social influencia de maneira contundente a Política Criminal, concebendo o que se denomina de "Política Criminal do risco". Nesse sentido, o Estado policialesco dissemina a vigilância permanente e demanda o gerenciamento do perigo ao passo em que a cultura do medo, difundida pela mídia, torna-se o centro das reflexões sociais e, não obstante, se transforma também no cerne das reflexões dogmático-penais.

Em sequência, ainda nessa seara, as ideias de expansão da tutela penal e de sua significativa ineficácia com relação à prevenção do fenômeno do crime e contenção da cólera social serão desenvolvidas através da teoria marginal deslegitimante do Direito Penal, da lavra de Eugênio Raul Zaffaroni, referenciada no presente artigo. Com esse enfoque, esforços serão envidados visando, sobretudo, se compreender como se efetiva, na práxis social, a dinâmica do poder punitivo e como a legitimidade do mesmo vem perdendo força na realidade das sociedades, principalmente no caso da América Latina, que é o alvo precípuo de reflexões da teoria zaffaroniana. 
Nessa linha de ideias, logo em seguida, buscar-se-á refletir melhor essa complexa e tênue legitimação do Direito Penal no que tange ao seu papel de intervenção social, mormente no seio da sociedade do risco, e se seria possível ao mesmo abarcar os novos desafios e situações vivenciados pelos indivíduos no contexto de um mundo que está em processo de constantes mudanças. Em tal sentido, é público e notório que o Direito Penal, na atualidade, passa por um grave e singelo momento de crise de legitimidade e que essa situação tem gerado inúmeras consequências gravosas no bojo de sua aplicação na realidade social, tais como a constante criação de novos tipos penais, o agravamento das penas já existentes, dentre outras. Ademais, essa nefasta faceta do Direito Penal Simbólico se envereda em um caminho frontalmente oposto às garantias estabelecidas nos princípios fundamentais da tutela penal, bem como confronta a verdadeira legitimidade do Direito Penal, arvorando-se como um instrumento simplista na resolução de um problema tão complexo que é a criminalidade.

Após essas ponderações críticas da atual tutela penal, tentar-se-á retomar quais seriam as diretrizes ideais para que o jus puniendi estatal recupere a sua legitimidade e a sua característica maior de respeito aos direitos humanos. Para tanto, os princípios da lesividade e da intervenção mínima serão analisados e, principalmente, referenciados enquanto verdadeiros norteadores da aplicação do Direito Penal que a sociedade realmente necessita e espera: fragmentário, subsidiário, mínimo e fortemente garantidor da dignidade da pessoa humana.

Por fim, a guisa de conclusão, através dessas reflexões, perquirir-se-á demonstrar a urgente necessidade da aplicação de um Direito Penal Mínimo no Estado Democrático de Direito, tendo como referencial-mor o princípio basilar de supremacia da Constituição e os valores e garantias processuais que permeiam esse modelo de estado, edificado, principalmente, com base no princípio da dignidade da pessoa humana. Afinal, uma democracia real e efetiva exige uma proteção ativa e pujante aos direitos dos cidadãos e, de outro lado, um maior controle dos deveres do Estado. Apenas dessa forma é que será possível atingir a maximização da liberdade e a minimização do poder de punir do Estado. 


\section{A PERNICIOSA EXPANSÃO DO DIREITO PENAL E A TENDÊNCIA DE SUA FUNCIONALIZAÇÃO}

O processo de democratização vivenciado pela sociedade atual demonstrou uma tendência da mesma em se interessar por assuntos públicos, tais como o crime e a insegurança pública. Émile Durkheim (1999), no berço da sociologia criminal, preconizava que um comportamento somente poderia ser considerado como crime quando atentasse contra os estados fortes da consciência coletiva. Dessa forma, um assunto coletivo de tamanha importância deveria interessar aos indivíduos que desejassem participar na esfera pública.

É sabido que o poder punitivo exercido pelo Estado deve ser entendido como uma questão política fundamental, como bem assevera o contratualista Thomas Hobbes (1993), haja vista que ao Estado é cedido o direito de punir, não se confundindo, por certo, com a antiga faculdade da vingança privada dada aos cidadãos. Dessa sorte, tem-se constatado o interesse cada vez mais pungente da massa popular pela temática do crime e da segurança pública. Em outro senso, o modelo de democracia representativa brasileiro e a crescente criminalidade fizeram com que o processo de democratização fosse deturpado. A sociedade moderna então se tornou uma "sociedade de risco", na medida em que passou a vivenciar o perigo como uma normalidade. A violência foi a responsável por gerar uma sensação coletiva de insegurança, impulsionada pelos meios de comunicação, que, a todo o momento, transmitem mensagens aos telespectadores, fazendo com que estes sejam vítimas em potencial e retratando a sociedade como desestruturada.

Aliado a isso, os indivíduos vivem em uma verdadeira sociedade do espetáculo, com a presença marcante da manipulação midiática, consubstanciada de carga sensacionalista, valorizando a violência e acentuando o interesse pelo crime (BARATTA, 2002). Este discurso sensacionalista desenvolvido pela mídia constitui-se, segundo Aury Lopes Junior "uma manipulação discursiva em torno da sociologia do risco, revitalizando a falsa crença de que o Direito Penal pode restabelecer a ilusão de segurança" (LOPES JÚNIOR, 2003, p. 18).

Analisando o grande poder da mídia, Vera Malaguti, referenciando Nilo Batista, ensina o seguinte:

Por isso, os discursos que matam, hoje, começam na mídia, a principal protagonista da questão criminal; e ela quem dispõe da maior concentração de poder penal. É a matéria do Jornal Nacional de hoje que pautará amanhã a ação da polícia, do Ministério Público e da máquina mortífera em geral. Segundo Nilo Batista "os esgares do âncora de um telejornal com boa audiência são mais importantes para a política criminal brasileira do que a produção somada de nossos melhores criminólogos e penalistas. (BATISTA, 2003, p. 44) 
Dessa forma, o Brasil tem se orientado pelo discurso criminológico midiático, pautado numa articulação retórico-demonstrativa, como bem assevera Nilo Batista:

\begin{abstract}
O novo credo criminológico da mídia tem seu núcleo irradiador na própria ideia de pena: antes de mais nada, creem na pena como rito sagrado da solução de conflitos. Pouco importa o fundamento legitimante: se na universidade um retribucionista e um preventista sistêmico podem desentender-se, na mídia complementam-se harmoniosamente. Não há debate, não há atrito: todo e qualquer discurso legitimante da pena e bem aceito e imediatamente incorporado a massa argumentativa dos editoriais e das crônicas. (BATISTA, 2002, p. 273)
\end{abstract}

Nesses termos, vale destacar as lições de André Luís Callegari sobre a politização do Direito Penal:

\begin{abstract}
A politização do Direito Penal por meio da utilização política da noção de segurança resulta de um empobrecimento ou simplificação do discurso político-criminal, que passa a ser orientado tão somente por campanhas eleitorais que oscilam ao sabor das demandas conjunturais midiáticas e populistas, em detrimento de programas efetivamente emancipatórios. (CALLEGARI; WERMUTH, 2010, p. 22)
\end{abstract}

Outra questão muito importante quanto à aplicação da Justiça Penal e seus reflexos é a própria funcionalidade do instrumento punitivo, caracterizado pela adoção de políticas de controle dos comportamentos criminosos através da instrumentalização da tutela penal para responder às transformações sociais. No entanto, o que se tem verificado na realidade prática é a maximização da capacidade funcional do Direito Penal, materializada mediante violações às garantias tradicionais. Consoante os precisos dizeres de Francisco Muñoz Conde, citado por Alberto Silva Franco, a funcionalização do Direito Penal "encerra o perigo de que lhe sejam atribuídas tarefas que na prática não pode cumprir, oferecendo, enganosamente, à opinião pública perspectivas de soluções de problemas que de imediato não se apresentam na realidade". (FRANCO, 1997, p. 2)

O Direito Penal funcional então deve ser compatível com uma intervenção punitiva mínima, de modo que "sejam protegidos os bens jurídicos mais relevantes" (SILVA SANCHEZ, 2002, p. 105). Esse referido processo de funcionalização está pautado em duas vertentes: a função promocional e a função simbólica. Na sociedade contemporânea a legitimação do Direito Penal é norteada enquanto instrumento de mudança e transformação social ou de imposição de novos valores. Ele deve intervir de modo ativo nas áreas de conflito, antes mesmo da atuação de outros controles sociais formais. Neste ponto, Francisco Muñoz Conde, citado por Franco (1997), destaca que, o Direito Penal é o "Direito por 
excelência", exercendo um grandioso fascínio na opinião pública e, apesar de existirem outros sistemas de regulação muito mais eficazes, só ele é capaz de despertar tamanha sedução. 
Todavia, conforme bem leciona Jorge de Figueiredo Dias (2004), a sociedade de risco, em que diversos países se enquadram, proporcionou uma “inflação penal” com o respectivo aumento dos aparatos de segurança pública, elevação das penas previstas para delitos já existentes e a criação de novas figuras delitivas. Nesse sentido, tem-se que:

A adequação do Direito Penal à sociedade do risco implica por isso uma nova política criminal, que abandone a função minimalista de tutela de bens jurídicos e aceite uma função promocional e propulsora de valores orientadores da ação humana na vida comunitária; e uma nova dogmática jurídico-penal disposta a abandonar e substituir princípios até aqui tão essenciais como os da individualização da responsabilidade penal e a considerar a nova luz questões como as da causalidade, da imputação objetiva, do erro e da culpa, da autoria. (DIAS, 2004, p. 128)

O problema é que tais tendências têm ocasionado efeitos perniciosos incompatíveis com a manutenção da tutela seletiva de valores elementares à vida comunitária, tanto que, o momento atual, protagonizado pela cultura do medo, afetou sobremaneira o Direito Penal. O pânico e o atordoamento gerado na população instigaram políticas invasivas e, muitas vezes, antidemocráticas de controle social. Acredita-se assim que a violência somente poderia ser controlada por meio do recurso ao Direito Penal.

A renovação da sociedade provocou o aparecimento de novas necessidades, novos costumes e novos pensamentos. Esse fenômeno, impulsionado pela globalização, trouxe para o Direito Penal um notável desequilíbrio no conflito entre segurança e liberdade. As mudanças sociais têm sido a força motora do expansionismo do Direito Penal e do abandono de seus traços democráticos. O Direito Penal clássico deixou de ser suficiente e satisfatório para tutelar as novas relações sociais, sendo exigida uma nova roupagem à ordem jurídica, marcada pelo crescente desenvolvimento social e econômico. Nesse sentido, como aduz Silva Sanchéz (2002), a adaptação do direito penal atual às novas necessidades de tutela impõe regras de comportamento que se estabelecem como função da pena e que abarquem os novos interesses da sociedade do risco.

Além dessa função meramente promocional, ao Direito Penal ainda cabe a função simbólica. Sabe-se que o Direito Penal, pela forma de repressão às ilicitudes e pela característica marcante de ser ultima ratio, se reveste de um símbolo. O recurso ao simbolismo enquanto instituto mostra-se válido e legítimo, uma vez que reconhece a força do Direito Penal.

Corroborando tal entendimento, Fernando Vernice dos Anjos leciona que: 
Fim simbólico seria aquele pelo qual não se objetiva, através do instrumental punitivo do Estado, a resolução efetiva de conflitos de interesses sociais ou a tutela real de bens considerados relevantes para a sociedade. Como o Direito Brasileiro sustenta que a missão do Direito Penal é a proteção de bens jurídicos, qualquer efeito simbólico da pena é considerado ilegítimo. De forma acrítica, tais efeitos da pena são frequentemente execrados ou simplesmente ignorados pela doutrina penal brasileira (ANJOS, 2007).

No entanto, de forma diversa, o Direito Penal simbólico tenta resolver os problemas da criminalidade e da segurança de forma ilusória, produzindo na opinião pública a impressão tranquilizadora de um legislador atento. Devido às grandes crises econômicas, políticas e sociais que vem alarmando a sociedade e gerando medo e insegurança coletiva, o recurso à função simbólica tem se mostrado bastante incidente nos últimos tempos. Esse simbolismo, na prática, é revelado pela edição de leis como resposta ao clamor público. Há exemplos significativos na legislação penal brasileira dessa funcionalização de caráter promocional, como por exemplo, novos tipos penais no Código de Defesa do Consumidor, nas leis contra a ordem tributária e econômica, na Lei de Crimes Hediondos, dentre outros. Busca-se editar normas de pouca ou nenhuma eficiência que tem o condão somente de dar uma resposta ligeira à população alarmada com as notícias sobre a criminalidade. Tais leis são elaboradas sem qualquer proteção efetiva na norma penal incriminadora, violando, dessa forma, o Direito Penal mínimo e o princípio da lesividade, uma vez que certas condutas são punidas de modo desnecessário, antecipando a punição e criminalizando comportamentos que não geram qualquer perigo real ou efetivo.

Acerca do tema, Paulo Queiroz alerta que,

(...) O legislador, ao submeter determinados comportamentos à normatização penal, não pretende, propriamente, preveni-los ou mesmo reprimi-los, mas tão-só infundir e difundir, na comunidade, uma só impressão e uma falsa impressão de segurança jurídica (QUEIROZ, 1999)

A referida funcionalização do Direito Penal não constitui um processo neutro, pelo contrário, está corrompido de inúmeras críticas. Alberto Silva Franco (1997) destaca que a funcionalização significa uma violenta agressão a um ponto nevrálgico do sistema penal, qual seja, a sua função formalizadora. Neste ponto, está a segunda tendência do Direito Penal moderno: a desformalização. Isso é crucial porque o Direito Penal, por lidar com os conflitos mais graves, requer um maior grau de formalização, não podendo conceber normas e sanções 
flexíveis. Exatamente por isso é que a desformalização constitui uma decorrência extremamente perigosa de um Direito Penal funcionalizado.

A desformalização dos instrumentos do Direito Penal Clássico, como ensinam Winfried Hassemer e Francisco Muñoz Conde (1989), é um dos caminhos pelos quais se pode

realizar a funcionalização do Direito Penal, eliminando ou diminuindo as barreiras tradicionais do Direito Penal garantista que podem limitar os fins políticos. Destarte, não é possível ainda se afirmar que a desformalização enriquece em alguma medida o Direito Penal ou, pelo contrário, diminui suas garantias formais. Os autores asseveram que um Direito Penal funcionalizado pela política criminal encontra a justificação de sua intervenção junto à opinião pública, além da possibilidade de se adaptar aos demais instrumentos políticos de solução dos problemas. O perigo de uma funcionalização do Direito Penal é o de eliminar ou reduzir as garantias de uma elaboração formalizada do conflito porque pode perturbar os fins e interesses políticos.

Citados autores ainda relatam que, com a desformalização do Direito Penal, o que se tem visto é a postura inócua do legislador, editando normas gerais indeterminadas, produzidas por vias distintas: pelo aumento do emprego de conceitos vagos e de cláusulas gerais nos preceitos legais; abstendo-se ou fazendo apenas referências sem especificar os fundamentos entre a criminalização e a descriminalização de alguns âmbitos de comportamentos ilícitos e deixando a cargo do julgador o poder discricionário de decisão, oferecendo-lhe conceitos com ampla margem interpretativa.

Nessa seara, o Direito Penal não pode ser transformado em um sistema de satisfação de expectativas e anseios da sociedade, sob pena de se transformar em um instituto desacreditado e ineficaz quanto à sua proposta original. $\mathrm{O}$ aumento de tipos penais e o rigor das penas não têm necessariamente potencial para resolver o problema da criminalidade, que cada vez mais atinge índices altíssimos. Em verdade, o caminho seria a elaboração de políticas públicas voltadas ao combate daquela, mas que, na prática, visualiza-se sempre a recorrência ao Direito Penal, com sua carga simbólica, capaz de satisfazer momentaneamente os anseios populares. Assim, é certo que o Direito Penal da era globalizada tende a ser crescentemente unificado, menos garantista, flexibilizando algumas regras de imputação e garantias político-criminais substantivas e processuais.

Em face dessas duas tendências — funcionalização e desformalização — o Direito Penal atual caracteriza-se, conforme Alberto Silva Franco: 


\begin{abstract}
Por uma ampla política de criminalização em áreas até então excluídas de sua intervenção, deixando de ser o instrumento mais adequado de tutela dos bens jurídicos mais relevantes contra os ataques mais graves a eles endereçados, para tornar-se o instrumento de uma política de segurança. Ao invés de ser utilizado como "ultima ratio" passa a ser adotado como "prima ratio" ou até mesmo como "sola ratio". Essas novas tendências desfiguram o Direito Penal cuja legitimação está vinculada ao estrito respeito aos princípios consagrados formalmente na Constituição Federal (princípio da legalidade, princípio da igualdade, princípio da culpabilidade e princípio da humanidade da pena) e ainda, aos princípios não inseridos no texto constitucional (princípio da exclusiva proteção dos bens jurídicos, princípio da intervenção mínima, princípio da proporcionalidade, etc.), mas que decorrem, implicitamente, do modelo jurídico adotado, ou seja, do Estado Democrático de Direito. (FRANCO, 1997, p. 2)
\end{abstract}

Diante das considerações até aqui realizadas, importa sobremaneira se analisar, de forma mais detida, o fenômeno da perda de legitimidade do Direito Penal contemporâneo e a sua acachapante ineficiência em lidar com as complexas realidades do crime e da delinquência. Essas ponderações serão feitas a seguir.

\title{
2- AS PENAS PERDIDAS: SIMBOLISMO, CONTROLE SOCIAL E A DESLEGITIMAÇÃO DA TUTELA PENAL
}

Em verdade, acompanhando o autorizado magistério de Eugênio Raúl Zaffaroni (1991), o sistema penal se constitui e se orienta por uma utópica legitimidade, pois, enquanto complexa manifestação do poder social, tem a sua legitimidade na "característica outorgada por sua racionalidade” (1991, p. 16), e, como o poder social não pode ser estático, já que é um exercício, um agir guiado e ponderado pelo caractere normativo, o sistema penal tenta se apresentar como um "exercício de poder planejado racionalmente”. A questão, porém, é que essa forma de apresentação não tem repercussão na realidade prática, pois a execução desse tal planejamento do sistema penal, isto é, o discurso jurídico-penal, não é racional, pelo que não pode então legitimar-se, já que "se esse discurso jurídico-penal fosse racional e se o sistema penal atuasse em conformidade com o sistema penal seria legítimo" (ZAFFARONI, 1991, p. 16).

Assim sendo, para Zaffaroni (1991) a coerência interna do discurso jurídico-penal e o seu valor de verdade quanto à operatividade social deveriam colaborar para que o sistema se legitimasse por si mesmo, contudo não há racionalidade, pois não há coerência nem mesmo internamente ao próprio sistema penal. Essa negação da própria coerência interna do discurso 
jurídico-penal salta à vista com argumentos positivistas como “assim diz a lei”, "é assim porque o legislador quer", e esses imbróglios são constantemente usados na América Latina e que demonstram mesmo a falha das tentativas de racionalização e de legitimação do exercício de poder do sistema penal (ZAFFARONI, 1991).

Um sintoma, na visão do mestre argentino, da deslegitimação sistêmica do Direito Penal é que o sistema penal não atua conforme a legalidade, sendo esta, em certo sentido, a operacionalidade real do sistema penal. A questão mesmo é que os órgãos que convergem do sistema penal não exercem seus poderes de acordo com a programação da lei oriunda do discurso jurídico-penal. Tanto assim que, no caso mesmo do Brasil, se constata o disparate entre o que diz a lei e o que acontece na prática. Apenas como exemplo, veja-se a lei $\mathrm{n}^{\circ}$ 7.210/84, a Lei de Execuções Penais, que traz conceitos bastante avançados e coadunados com a Dignidade da Pessoa Humana como seus objetivos de garantia do bem estar do condenado, necessidade de classificação do indivíduo e individualização da pena e assistência necessária dentro do cárcere (NUCCI, 2005). Basta se atentar para os arts. 10 a 25 da lei para se aquilatar o avanço da política de assistência ao preso, que dizer então do art. 40 que determina "a todas as autoridades o respeito à integridade física e moral dos condenados e dos presos provisórios"? Não é necessária uma análise muito aprofundada dos presídios e cadeias espalhados por esse país continental para que seja possível a constatação de que a realidade é bem diferente: o sistema prisional brasileiro está inflado de pessoas que se amontoam em condições degradantes e o Estado não consegue assegurar, nem em nível elementar, os preceitos trazidos no bojo da lei (GOMES, 2002).

Nesse sentido e constatando o avilte que é o sistema carcerário no Brasil, Guilherme de Souza Nucci assevera que,

\footnotetext{
na prática, no entanto, lamentavelmente, o Estado tem dado pouca atenção ao sistema carcerário, nas últimas décadas, deixando de lado a necessária humanização do cumprimento da pena, em especial no tocante à privativa de liberdade, permitindo que muitos presídios se tenham transformado em autênticas masmorras, bem distantes do respeito à integridade física e moral dos presos, direito constitucionalmente imposto.(NUCCI, 2005, p. 919)
}

Por fim, ainda neste exemplo, o que dizer ainda da "ressocialização" mencionada já no artigo inaugural da lei? Será que o sistema de execução penal, da forma como ele efetivamente funciona hoje no Brasil, propicia a "harmônica integração social do condenado"? 
Seguindo com a ideia zaffaroniana de legalidade, percebe-se então, pelo exposto, que nem sequer em nível prévio, nem mesmo primariamente, o exercício de poder do sistema penal é "legal". E a pretensa legalidade do discurso jurídico-penal desdobra-se, por princípio, na legalidade penal e na legalidade processual.

Por legalidade penal deve-se entender ser a exigência mesma de que o poder punitivo do sistema penal ocorra sob o filtro de limites que sejam a priori delimitados para a punibilidade (ZAFFARONI, 1991).

Já com relação à legalidade processual, seria ela a demanda de que os órgãos do sistema penal efetuem seus desideratos como tentativa de criminalização de todos os autores de ações típicas, antijurídicas e culpáveis, desde que este exercício se efetive segundo o que Zaffaroni designa como "certas pautas detalhadamente explicitadas" (1991, p. 21). O ponto aqui é que a execução desse poder, para além da somente ação conforme os ditames legais deveria sempre ser levada a bom termo pelo sistema penal.

Algo a ser relevado é o grifo que foi feito acima na expressão "criminalização de todos os autores de ações típicas, antijurídicas e culpáveis”. Ora, a legitimidade do discurso jurídico-penal já se mostra enfraquecida logo prima facie à constatação de que se tem um sistema que, além de parecer ter sido feito para não funcionar ou para só funcionar se selecionar determinados casos, não consegue tratar de todos os casos que se amoldam à norma penal incriminadora. Neste momento cabe trazer à baila que existe uma cifra negra da criminalidade que contamina o sistema penal, pois, conforme Rogério Greco (2010, p. 8) há uma "cifra negra correspondente às infrações penais que não foram objeto de persecução pelo Estado". Sobre isso, Bustos Ramirez e Hormazábal Malarée com precisão e clareza de ideias inigualável aduzem que,

\footnotetext{
A estatística criminal se confecciona a partir dos dados registrados pelos órgãos do controle social penal. Isso quer dizer que há um grande número de fatos puníveis que por não terem sido registrados não formam parte da estatística criminal. Estes fatos constituem a cifra negra da criminalidade. Com efeito nem todo delito é denunciado. Nem todos os delitos denunciados são registrados como tais pelo órgão ante o qual foi feita a denúncia. Nem todos os delitos denunciados e registrados pelo órgão que recebeu a denúncia são objeto de investigação e nem todos os investigados acabam sendo condenados. Deste modo, de acordo com o nível do órgão a partir do qual se elaborou a estatística, mais alta será a cifra negra. Dito em outras palavras, não é o mesmo elaborar estatísticas criminais a partir das sentenças condenatórias que dos fatos denunciados à polícia. Entre a comissão do delito e a sentença condenatória atuam uma série de filtros que não permitem contar com dados estatísticos confiáveis. (RAMIREZ; MALARÉE, 2004, p. 37, grifo nosso)
} 
Em análise mais acurada dessa preciosa lição sobre a cifra negra da criminalidade, pode-se resenhar que existem problemas internos graves dentro dos órgãos de investigação que compõem a "linha de frente" do sistema penal. Veja-se, em livre expediente imaginativo, mas que, frise-se, talvez em nada ou muito pouco se afasta do que seria a realidade, um exemplo de uma Delegacia Policial do sistema penal no Brasil. A primeira situação colocada pelos autores, que se coaduna também com a precisa visão de Augusto Thompson (2007), é a denúncia e, neste ponto até, que não há tanta responsabilidade dos agentes do sistema, pois nem todo o delito é denunciado, e, como a Delegacia funciona através da notitia criminis, isto é, a autoridade policial precisa tomar conhecimento, seja de maneira espontânea ou provocada, de um fato aparentemente criminoso, então, se essa informação sobre o fato não chega ao conhecimento da autoridade policial, não há como agir e iniciar a investigação criminal. A segunda situação, todavia, já implica no inicio da responsabilização dos agentes, pois se pondera que "nem todos os delitos denunciados são registrados como tais", de fato, se efetivada uma denúncia junto à autoridade policial e esta não agir, desconsiderando a informação por entender não ser caso de ação policial ou por considerar não haver crime nem a princípio ou mesmo por pura conivência e desídia por já ter sobre si uma excessiva e quase impraticável demanda de trabalho, estará a autoridade colocando uma "pá de cal" e privilegiando a impunidade do possível delito cometido. Com relação a terceira e última situação em tese da cifra negra, conforme o excerto referenciado, "nem todos delitos denunciados e registrados pelo órgão que recebeu a denúncia são objeto de investigação e nem todos os investigados acabam sendo condenados", tem-se a ocorrência, primeiramente, do "engavetamento do caso" pela autoridade que, mesmo recebendo a denúncia, não procede com a investigação, arquivando o caso e, mais uma vez, deixando de fazer agir a máquina penal. Por fim, quando a denúncia é devidamente tratada e a autoridade policial procede com a investigação, ainda existem outros filtros no sistema que impedem que se tenha a condenação como resultado último.

Portanto, retomando o raciocínio zaffaroniano sobre o discurso jurídico-penal, tem-se que não é ele legítimo por não ser legal, e mais, por possuir uma lógica interna e estrutura tais que o deslegitimam. É este um contexto tal em que a própria dimensão legal, a própria lei abdica dos limites da legalidade, desaparecendo mesmo então as funções de garantia dos tipos penais e excluindo a normal intervenção dos órgãos judiciais, de uma tal sorte que será este contexto exatamente a base imprescindível em que se operará o verdadeiro exercício de poder do sistema penal, seria o "poder configurador" (ZAFFARONI, 1991, p. 23). 
Este tal poder, enquanto renúncia indubitável à legalidade penal se encarrega de um “controle social militarizado e verticalizado" através dos órgãos do sistema penal, que o exercem sobre a sociedade. Zaffaroni, ampliando o termo, aduz que o "poder configurador" seria mesmo um poder "militarizador e verticalizador-disciplinar" (ZAFFARONI, 1991, p. 23).

Na verdade, Direito Penal e Controle Social seriam, em uma livre observação, duas faces da mesma moeda (BARATTA, 2002). O ponto principal aqui é que o Controle Social seria justamente a face oculta dessa moeda, pois, veladamente, o Direito Penal se apresenta como uma hábil ferramenta de Controle Social, haja vista a sua forte tendência em enquadrar pessoas com fulcro mais na condição social do que nas eventuais condutas delitivas, tendo, ao seu dispor, a concentração do poder controlador ( $v \cdot g$, polícia, etc) sob a responsabilidade do Poder Executivo e, bem como, a ingerência do mesmo nos organismos institucionalizados de atuação do Direito Penal.

A face oculta do Controle Social através do Direito Penal se revela, não através do processo e condenação de um delito específico, pois esta seria uma exerção ínfima a se realizar muito eventualmente e de forma altamente seletiva e com bastante publicidade pelos meios de comunicação de massa, mas sim mediante o que Zaffaroni chama de "interiorização dessa vigilância disciplinar" (1991, p. 24) por parte significativa da população. Inclusive, para que esta interiorização seja eficaz é fundamental justamente esse papel midiático, "espetacularizante", dos meios de comunicação de massa. Nesse sentido mesmo, Julio Fabbrini Mirabete observa que é,

Prejudicial tanto para o preso como para a sociedade é o sensacionalismo que marca a atividade de certos meios de comunicação de massa (jornais, revistas, rádio, televisão, etc). Noticiários e entrevistas que visam não a simples informação, mas que tem caráter espetaculoso, não só não atentam para a condição da dignidade humana do preso como também podem dificultar a sua ressocialização após o cumprimento da pena. (MIRABETE, 2000, p. 132)

A mídia cumpre então papel decisivo quando o discurso jurídico-penal exerce o seu "real poder". Este poder, que atua através da "vigilância disciplinar verticalizante e militarizada" da sociedade, se operacionaliza de forma camuflada, de maneira mesmo a impedir a percepção consciente da sociedade sobre a sua atuação, daí porque as pessoas que são as mais vulneráveis à ação do sistema penal (fala-se aqui, evidentemente, dos mais pobres e dos marginais sociais, dissidentes), se, de uma forma não ficam impactadas ante ao exercício de poder do sistema penal que por vezes surge com sua mira apontada para o 
inimigo, de outra "percebem como temível o exercício de poder dos órgãos do sistema penal controlando qualquer conduta realizada em lugar público ou privado" (ZAFFARONI, 1991, p. 25).

Veja-se que o professor argentino observa que esse tal controle das condutas, essa fiscalização dos comportamentos, seja em locais públicos ou particulares, por se realizar de maneira camuflada dentro do sistema e por isso denotar o seu real exercício de poder, talvez seja até pior, em certa medida, à espetacularização promovida pelo sistema quando seleciona o "inimigo", o "bode expiatório" que servirá de modelo de demonstração de que o Direito Penal está funcionando e protegendo as pessoas ao punir exemplarmente os criminosos, isso porque atua sorrateiramente, atingindo mesmo a vida privada das pessoas, principalmente as mais carentes que não tem privacidade, ou a tem de maneira reduzida nos espaços urbanos.

Por isso que não há como escapar ao sistema, e aqui se pode criticar no sentido de que especialmente se a pessoa for das camadas mais carentes não pode fugir ao controle do sistema penal que incide a sua vigilância sobre praticamente qualquer conduta.

Por fim, concluindo as ideias de perda da legitimidade e da legalidade no seio da lógica estruturante do discurso jurídico penal, Zaffaroni preleciona que,

\footnotetext{
Em síntese, e levando-se em conta a programação legal, deve-se concluir que o poder configurador ou positivo do sistema penal (o que cumpre a função de disciplinarismo verticalizante) é exercido à margem da legalidade, de forma arbitrariamente seletiva, porque a própria lei assim o planifica e porque o órgão legislativo deixa fora do discurso jurídico-penal amplíssimos âmbitos de controle social punitivo. (ZAFFARONI, 1991, p. 25)
}

O Direito Penal ou o discurso jurídico-penal é ilegítimo também porque, no exercício de suas funções declaradas, tem-se como resultado problemas e infelicidades incalculáveis. Assim é que, na feliz e peculiar colocação de Alessandro Nepomoceno (2004), o Direito Penal funciona como quando alguém vai efetuar a aquisição de um carro. $O$ indivíduo analisa o veículo, constata o seu estado aparente de boa conservação, checa manual, documentos e etc, aparentando estar tudo muito certo. Quando se dá a partida no carro vem a ingrata surpresa: ele não funciona bem como se desejaria, o motor precisa de reparos, embora seja até possível o seu uso, ele chega a comprometer a segurança dos passageiros e até das pessoas na rua. É assim o real funcionamento do sistema penal moderno, ele possui promessas, planos de ação que não são e não podem ser cumpridos (ROXIN, 1997), como um eficiente desempenho na luta contra a criminalidade e a falsa reverberação de sentimentos de segurança 
e pacificação social - pois a lei penal, ainda que severa, está sendo aplicada, por exemplo, e cumpre o que não foi dito, reproduzindo o status quo mediante a penalização e eleição de uma minoria a sofrer as agruras do sistema.

A legitimidade do Direito Penal, portanto, por não encontrar, absolutamente, sustentação nem mesmo na legalidade, se perde completamente, já que passa a dialogar com uma função verdadeira do discurso jurídico-penal, através da execução de um poder configurador disciplinarizante (ZAFFARONI, 1991), que não encontra respaldo no ordenamento jurídico, e, embora ilegal, continua a se reproduzir, pois os problemas do sistema penal são sistêmicos, estruturais. Nessa direção importa ponderar que uma coisa é a lei, a abstrata previsão legal, outra é a realidade prática, a operacionalização do sistema penal, sobretudo no Brasil em que chega mesmo ao nível de disparate a comparação do diploma legal com a realidade, o mundo dos fatos.

Assim sendo, uma vez vistas as críticas ao modelo de Direito Penal máximo, à sua constante expansão e a severa perda que tais condicionantes tem ocasionado no que se refere à sua legitimação para agir na sociedade, importa então se aquilatar em que termos se encontra o jus puniendi do estado contemporâneo e quais seriam os seus desafios, na forma como se verá no tópico seguinte.

\section{3- A LEGITIMIDADE DO ESTADO EM PROIBIR CONDUTAS E A NOVA FEIÇÃO DO DIREITO PENAL MODERNO}

Iniciando a reflexão sobre a legitimidade do Estado em proibir condutas, merece destaque a passagem de Mir Puig Santiago (2007, p. 92), o qual aduz que "se o Direito penal de um Estado social só se legitima na medida em que protege a sociedade, perderá sua justificação caso a intervenção demonstre-se inútil por ser incapaz de evitar delitos”. Dessa forma, para ele, quando se criminaliza condutas desnecessariamente, o sistema penal perde legitimidade, pois, por um lado, não consegue combater todas as condutas criminalizadas e, por outro, a sociedade, em longo prazo, notará que o sistema é falho e que seus agentes são incapazes de garantir a segurança e lidar com a criminalidade, o que gerará um efeito em cadeia.

A intervenção jurídica deve buscar, por conseguinte, a máxima eficácia preventiva e a certeza do castigo, preservando integralmente os direitos fundamentais do acusado, 
conciliando com a nova feição dada ao Direito Penal, marcado pela era do simbolismo, da globalização e do garantismo penal. Estabelecer os limites além dos quais essa intervenção mostrar-se-á ilegítima é tarefa minuciosa e dependerá de uma análise com fundamento nos princípios fundamentais que norteiam a Dogmática Penal.

O maior desafio do Direito Penal, seguindo esse raciocínio, seria conseguir conciliar as novas exigências preventivas com as garantias jurídico-penais tradicionais, de forma que se instaure um quadro de legitimação. Para um eficaz domínio da criminalidade, o Estado deve ater-se aos bens jurídicos mais importantes, devendo intervir na exata medida requerida para o asseguramento das condições essenciais de funcionamento da sociedade. Nesse sentido, a função que ainda confere legitimidade ao Direito Penal que se desenvolve nos Estados Democráticos de Direito é a da tutela fragmentária e subsidiária de bens jurídicos.

Cabe assinalar que a legitimidade do direito penal e, consequentemente, da pena, conforme preleciona Luigi Ferrajoli (2010), enquanto meio através do qual se objetiva a proteção dos direitos fundamentais, não é meramente formal, mas sim materialmente democrático, no sentido de instrumento destinado à tutela de valores e de direitos fundamentais. $\mathrm{O}$ referido autor bem destaca que

Esta legitimidade [...] não é 'democrática' no sentido que não provém do consenso da maioria. É, sim, 'garantista', e reside nos vínculos impostos pela lei à função punitiva e à tutela dos direitos de todos. 'Garantismo', com efeito, significa precisamente a tutela daqueles valores ou direitos fundamentais, cuja satisfação, mesmo contra os interesses da maioria, constitui o objetivo justificante do direito penal, vale dizer, a imunidade dos cidadãos contra a arbitrariedade das proibições e das punições, a defesa dos fracos mediante regras do jogo iguais para todos, a dignidade da pessoa do imputado, e, consequentemente, a garantia da sua liberdade, inclusive por meio do respeito à sua verdade. (FERRAJOLI, 2010, p. 312)

É incontestável a atualidade do tema da crise de legitimidade do Direito Penal no âmbito das ciências penais, conforme, inclusive, já se pôde constatar anteriormente neste presente trabalho, e, por isso, requer uma análise hermenêutica profunda, com um viés críticoconstrutivo que colabore para o desenvolvimento da ciência penal, já que, nas palavras de Muñoz Conde:

[...] não se pode aceitar que a atividade do jurista possa se limitar à mera constatação da situação. Para além de mera descrição, deve-se analisar a compatibilidade desse pretendido Direito com os princípios do Estado Democrático de Direito e com os direitos fundamentais consagrados na Constituição e nas declarações internacionais de direitos humanos. O jurista não pode, assim, ser simplesmente um mensageiro, transmitindo a má notícia, classificando-a por meio de um nome; deve analisá-la criticamente, não a partir de razões ideológicas ou políticas, mas sim por razões estritamente jurídicas (CONDE, 2005, p. 82-83) 
Sob outro enfoque, como conciliar o Direito Penal Simbólico com a atuação do Estado e a respectiva legitimidade dessa atuação? Seria legítimo ampliar a atuação do Direito Penal para abarcar os novos riscos? Tais questionamentos retratam as principais dúvidas que pairam no âmbito das ciências penais na atualidade. No entanto, a resposta para isso dependerá de um prévio estudo das causas que promovem a angústia coletiva da pósmodernidade, algo que ainda está longe de ser plenamente compreendido e desmitificado. $A b$ initio, parece um contra senso admitir que o Direito Penal deva permanecer estático, ao contrário, ele deve ser compreendido à luz das características em que é aplicado, ou seja, como um sistema dinâmico e aberto.

Surge, então, uma proposta de conceder ao Direito Penal a roupagem que lhe é necessária frente às necessidades sociais incipientes. Intensifica-se assim o uso de determinados institutos, mitigando algumas garantias clássicas para proporcionar a maior eficácia possível na luta contra a delinquência e contra o criminoso, visto como inimigo. Nesse sentido, é imperioso afirmar que o modelo clássico de Direito Penal não mais atende aos desafios impostos pela pós-modernidade e está, conforme visto, em acentuado declive e colapso. A crise estrutural do sistema punitivo para lidar com as novas demandas da sociedade de risco se reflete na profunda crise de legitimação do Direito Penal.

A reflexão sobre as indagações outrora realizadas ainda impõe o embate entre a estabilização de um "Direito Penal do risco" e a violação de princípios e garantias penais de índole liberal. Nesse ponto, revelam-se duas tendências criminológicas opostas: aqueles que defendem a limitação da atuação do Direito Penal ("discurso de resistência") e outros que pregam a funcionalização do Direito Penal. Luigi Ferrajoli (2010), mostra que, ambas as teses, antagônicas, ou pretendem legitimar a intervenção penal em novos âmbitos da atividade social ou intentam reduzir sua ingerência ao tradicional e inafastável núcleo antropológico do Direito Penal clássico. O referido autor ainda pondera que a sanção penal também deve encontrar legitimidade no contexto do Estado de Direito sob um enfoque utilitário, ou seja, deve-se considerar "além do máximo bem-estar possível dos não desviantes também o mínimo mal-estar necessário dos desviantes”. Nessa linha, é possível afirmar que o direito penal destina-se à proteção do fraco contra o mais forte, tutelando o ofendido em relação ao delinqüente.

De outra sorte, o Direito Penal meramente simbólico não se coaduna com os objetivos e ideais da tutela penal, haja vista que não observa os limites estabelecidos pelos 
princípios da lesividade ou ofensividade e, bem como, da intervenção mínima, como se verificará no próximo tópico.

\section{4- OS PRINCÍPIOS DA LESIVIDADE E DA INTERVENÇÃO MÍNIMA COMO NORTEADORES DO DIREITO PENAL}

Embora existam muitas e severas controvérsias acerca da feição ilegítima, autoritária e seletiva que revelam os matizes nos quais o Direito Penal é aplicado na realidade diária que envolve o fenômeno do fato social, na forma mesmo como se viu até aqui no artigo em tela, afigura-se então indispensável resgatar alguns postulados que, pelo menos em linha axiológica e na forma como os pesquisadores penalistas bem asseveram, devem ou, pelo menos, deveriam inspirar e nortear todas as esferas de incidência do Direito Penal atual no presente tempo. Dentre tais postulações, os ideários da lesividade ou ofensividade e da intervenção mínima, ainda que básicos ou primários de um Direito Penal Garantista, são dos mais importantes para a plena consagração de um verdadeiro Direito Penal Mínimo, que é o modelo teórico-penal mais alinhavado com a efetiva proteção aos direitos humanos e, especialmente, a dignidade da pessoa humana, preceitos estes tão valiosos ao atual estágio de consolidação do Estado Democrático de Direito.

\subsection{O ideário da lesividade ou ofensividade}

Nesse contexto, o principio da lesividade deve sempre inspirar o legislador quando da criação de uma hipotética figura típica. Isto porque o raciocínio primordial que deve incidir sobre ele é o concernente à aferição efetiva e ponderada acerca da importância do bem jurídico selecionado que irá receber a atenção e a proteção do Direito Penal. Assim sendo, tem-se que a lesividade pressupõe uma verdadeira ofensa ao bem jurídico objeto de tutela pela norma penal, conforme sintetiza o antigo brocardo nullum crime sine injuria. Então, evidencia-se aqui um crucial limite à incidência do moderno jus puniendi estatal, pois a ofensa que deve ser objeto da reprimenda penal deve bem revelar-se intolerável (BIANCHINI; GOMES, 2009), posto que a mesma precisa, de forma indispensável, ofender concretamente o bem jurídico em questão. 
Em face deste raciocínio, o insigne Nilo Batista apresenta quatro referenciais que são fundamentais no seio do principio da lesividade, quais sejam:
a) proibição de incriminações que digam respeito a uma atitude interna do agente;
b) proibição de incriminações de comportamentos que não excedam ao âmbito do próprio autor;
c) proibição de incriminações de simples estados ou condições existenciais;
d) proibição de incriminações de condutas desviadas que não afetem qualquer bem jurídico.(BATISTA, 1996, p. 92-94)

Em verdade, esses referenciais resumem, segundo Rogério Greco (2010), uma regra primordial que aduz que o Direito Penal, consoante o mandamento da lesividade ou ofensividade, apenas pode coibir condutas que ultrapassem a realidade pessoal do próprio agente e que ofendam bens de outrem. Tal ideário é de suma importância na realidade constitucional do Estado de Direito, uma vez que os pensamentos, a mera cogitação, os comportamentos pessoais (ainda que destoantes da dita moral costumeira), não podem sofrer a incidência do Direito Penal, como, inclusive, aconteceu em tempos remotos dos séculos $\mathrm{X}$ a $\mathrm{XV}$, especialmente no período da Inquisição, em que pessoas eram investigadas, acusadas, condenadas e afinal executadas, de forma absolutamente sumária ou sumaríssima, apenas por pensarem diversamente da Igreja na época, por serem consideradas "hereges".

Nessa linha de ideias, Luiz Flávio Gomes (2002) leciona que a ofensividade seria uma condito sine qua non, mesmo que não suficiente ou que não a única, para que ocorra a intervenção penal, de modo que o delito seria a expressão da infração ao Direito, o que demanda ao legislador clarificar obrigatoriamente a descrição do fato típico enquanto ofensa direta a um bem jurídico específico e determinado. Continuando esse mesmo raciocínio do referido autor, é imperioso notar o questionamento que a doutrina penalista realiza com relação a diversas infrações penais, que, quando são submetidas ao inafastável "teste da lesividade", acabam por ter a sua validade sucumbida. Assim é que, sob essa condição, seria extremamente difícil, por exemplo, sustentar a validade daqueles tipos penais que prefiguram crimes de "perigo abstrato", é exatamente nessa direção que se aponta que

Os delitos de perigo abstrato não podem ser admitidos em um Direito Penal baseado no princípio da lesividade. A mera presunção de que certas condutas podem afetar a terceiros não basta para legitimar a ingerência punitiva se essa afetação não se produz realmente no caso concreto. (SILVESTRONI, 2004,p. 207) 
Assim também algumas contravenções penais como a vadiagem, embriaguez, etc, já estariam superadas com base na lesividade. Porém, um dos casos mais emblemáticos nessa discussão é o referente ao consumo pessoal de entorpecentes, consoante o art. 28 da lei 11.343 2006. Na visão do conceituado Prof. Nilo Batista (1996), a conduta perpetrada pelo usuário de drogas não ultrapassaria o âmbito do mesmo, pelo que ele considera que tal incriminação estaria em colisão direta com o princípio da lesividade e, bem como, com o melhor entendimento doutrinário acerca de política-criminal. Para tanto, o autor ensina que isso seria o mesmo fundamento que inibe a que a autolesão seja punida, pelo que seria uma conduta externa que, mesmo que atacando formalmente um bem jurídico, não estaria a ultrapassar o âmbito do próprio autor, assim como ocorre no suicídio, na automutilação e bem deveria ocorrer neste específico caso de uso de drogas.

Portanto, em face do exposto, a lesividade deve então atuar como um verdadeiro princípio garantista, ao passo em que se impera a sua interpretação conjuntamente com outros relevantes princípios, tais como o da intervenção mínima, da fragmentariedade, da subsidiariedade e da insignificância, todos tendo como sustentáculo basilar o princípio último da dignidade humana. A importância do referido principio para o Direito Penal moderno, em apertada síntese, seria a imposição de limites bem delineados ao jus puniendi estatal, dandolhe um sentido humano, limitador e político, sobretudo em face do severo e conturbado contexto social dos dias atuais, em que sói ocorrer o embrutecimento do aparelho penal e, bem como, o exponencial crescimento de discursos puramente retribucionistas.

\section{2- O princípio da Intervenção Mínima}

O principio da intervenção mínima se apresenta como mais uma das linhas axiológicas cruciais e de obrigatória observância no moderno Direito Penal Garantista, posto que o mesmo devolve a instância penal ao locus político e social do qual ela nunca deveria ter saído, isto é, à condição de acessória, de mais uma das forças estatais à disposição no auxílio a resolução de conflitos. Tal ideia revela uma conquista da sociedade, pois prenuncia o Direito Penal como um dos últimos recursos para conter os conflitos, devendo o mesmo se apresentar apenas quando outras instâncias da sociedade e do direito se mostrarem insuficientes à resolução do fato social. 
Isso posto, inicialmente, com Rogerio Greco (2010), cabe verificar as duas ênfases fundamentais que devem ser dadas ao referido principio, quais sejam o entendimento de ser a intervenção mínima um principio de análise abstrata que serve de orientação ao legislador no momento da criação ou revogação de condutas típica e a particularidade revelada na natureza subsidiária do Direito Penal, que deve sempre ser concebido e tratado como a ultima ratio de intervenção do Estado.

Quanto à primeira ênfase, impende evidenciar a finalidade última do principio, que acaba por ser também do próprio Direito Penal, que, em conceituação minimalista, seria a proteção tão somente daqueles bens considerados mais caros e indispensáveis à convivência em sociedade. No que tange ao segundo enfoque do principio em comento, veja-se que o Direito Penal impende ser aplicado, por força de sua dramática e rígida reprimenda, de uma maneira que a doutrina consignou alcunhar de "subsidiária", isto é, privilegiando, a priori, que os outros diversos ramos do direito tentem agir com fulcro na proteção dos bens jurídicos, de tal forma, portanto, que o Direito Penal apenas será conclamado à ação no iminente instante em que esses ramos demonstrarem ineficiência na devida proteção dos bens referidos.

Nessa linha de ideias, importa trazer brevíssimas considerações sobre a questão da construção teórica atinente ao que seria um bem jurídico fundamental, porém sem entrar no mérito das controvérsias a esse respeito, por não ser objeto do presente artigo. Dessa maneira, sinteticamente, as lições preciosas de Bustos Ramirez e Hormazábal Malarée apontam que

Os bens jurídicos considerados materialmente são relações sociais concretas que surgem como síntese normativa dos processos interativos de discussão e confrontação que tem lugar dentro de uma sociedade democrática. São dinâmicos, pois estão em permanente discussão e revisão. (RAMIREZ; MALARÉE, 1997, p. 59)

Assim sendo, independente da consideração particular ou coletiva da ideia de bem jurídico, que geralmente ocorre na doutrina, o que importa para os fins colimados pela intervenção mínima é que os bens selecionados para a incidência da reprimenda penal sejam os mais valiosos possíveis para o corpo social. Isso é de tanta relevância que, conforme aponta Rogério Greco (2010), Luigi Ferrajoli (2006), sopesando os crimes com as contravenções, acaba por ser incisivo na consideração de que as contravenções deveriam ser extirpadas do ordenamento jurídico, sob o argumento de que, em face do raciocínio abstrato da pena que revela a gravidade do injusto penal, como as mesmas não tem tanta importância uma vez que não mereceram a proteção pela via das figuras típicas, elas deveriam ser abolidas com a 
consequente defesa dos bens protegidos pelas mesmas a ser efetuada pelos demais ramos do ordenamento jurídico.

Veja-se claramente que o raciocínio de Ferrajoli se coaduna exatamente coma verdadeira "pregação" garantista da consideração do Direito Penal enquanto ultima ratio, que deve ser relevada em toda a esfera jurídico-penal, revisando mesmo os próprios comandos da política criminal. Exatamente nessa direção é que o mestre Claus Roxin assevera que o Direito Penal seria apenas

\footnotetext{
a última dentre todas as medidas protetoras que se devem considerar, quer dizer, que somente pode intervir quando falharem outros meios de solução social do problemacomo a ação civil[...], as sanções não penais etc. Por isso se denomina a pena como ultima ratio da política social e se define sua missão como proteção subsidiária de bens jurídicos. (ROXIN, 1997, p. 65)
}

Por fim, importa destacar, em face do grave contexto de expansão da tutela penal e do seu uso "simbólico", que o verdadeiro Direito Penal constitucional é aquele que intervém minimamente na vida dos indivíduos, que age em função dos bens jurídicos mais importantes, ou seja, não se presta a combater condutas de pouca gravidade, mas apenas os atos mais gravosos que realmente causem danos irreparáveis a valores de imperiosa observância para o corpo social.

Nessa direção, afinal vistos os norteadores principais do verdadeiro Direito Penal, cabe se encaminhar então para o permanente desafio da tutela penal que é sempre fiscalizar a sua atuação garantidora de direitos fundamentais, no que se mostra imperioso garantir efetivamente um Direito Penal mínimo no Estado de Direito, tema este que será visto a seguir.

\section{5- A GARANTIA DE UM DIREITO PENAL MÍNIMO NO ESTADO DEMOCRÁTICO DE DIREITO}

O Direito Penal tem por função precípua a proteção de bens jurídicos, não podendo ser estes considerados fim em si mesmo. Aquele deve buscar a proteção da sociedade de ataques a direitos individuais ou coletivos que sejam essenciais à dignidade e à existência do cidadão e do Estado. Nas palavras de Juarez Cirino dos Santos, o Direito Penal tem por função a "proteção de valores relevantes para a vida humana individual ou coletiva, sob ameaça de pena" (SANTOS, 2010, p. 5). 
Sendo conhecida a função do Direito Penal, cabe ressaltar que, em um Estado Democrático de Direito, mister se faz a aplicação de um Direito Penal Mínimo. Embora seja crível que os problemas da sociedade não se resolverão através do Direito Penal, que até mesmo o tormento da criminalidade o Direito Penal não consegue aplacar, há uma insistência das esferas de poder constituídas, talvez em virtude da poderosa e inexorável influência das espetacularizações midiáticas dos órgãos de comunicação de massa e da força dos discursos máximos de dura repressão da criminalidade que agradam a sociedade, em fazer uso do Direito Penal de forma abusiva e, por vezes, "propagandista", como se estivessem querendo transmitir uma sensação de segurança jurídica e paz social que somente com o Direito Penal seria possível alcançar. O Estado Democrático de Direito não permite que a Justiça Penal se sensibilize com a opinião da maioria, que luta por uma política criminal de retribuição, marcada pelo midiatismo e pelo sensacionalismo jornalístico, valorizando a posição da vítima e sempre diabolizando os acusados.

O que acontece é a aplicação dura do Direito Penal repercutindo na práxis do fato social, ainda que o arcabouço teórico dessa aplicação, nos dias atuais, seja ou queira ser garantista. O problema está mesmo nesse sentido, precisamente como já restou demonstrado nesse artigo, na dicotomia entre a teoria e a realidade (ZAFFARONI, 1991), pois uma coisa é a ideia atual do sistema querer ser garantista (embora, na prática, se saiba que ele é repressor e desigual) e outra é se conjecturar que essa ideia seja maximalista, de Direito Penal do Inimigo.

O destacado Luigi Ferrajoli (2006) bem leciona que o Judiciário, em um Estado Democrático de Direito, quando chamado a exercer o controle judicial do crime e o poder de punir, tem a obrigação política de tutelar os direitos fundamentais, que são bens jurídicos que nenhum agente, público ou privado, está autorizado a lesionar, seja com delitos, seja com castigos. Nesse sentido, hodiernamente, a Justiça Penal, ao menos em linha teóricoaxiológica, está pautada nos valores de proteção dos direitos fundamentais, não podendo se submeter a uma política criminal maximalista, de feição vingativa e restritiva de garantias, ainda que pressionada pela maioria.

Salienta-se assim que a tese mais destacada do Maximalismo Penal, que é o Direito Penal do Inimigo (ZAFFARONI, 2007), ainda que queira se afirmar legítima e escorada em um tratamento ao inimigo que seja endossado pelo parâmetro normativo, muito se afasta das ideias de legitimidade do Direito Penal, uma vez que está mais do que claro que a propagação de um estado policialesco, de um estado de guerra permanente à criminalidade com retirada 
de garantias e imposição de gravosas medidas às pessoas, além de não resolver os problemas da sociedade com relação à criminalidade, ainda se constitui num verdadeiro passo atrás na grave história de lutas pela conquista do respeito as liberdades e aos direitos e garantias fundamentais dos cidadãos.

Dessa forma, o sistema constitucional vigente reclama acintosamente por uma atuação judicial realmente garantista, pautada na prevenção geral dos delitos e das penas arbitrárias, limitada ao conteúdo dos direitos fundamentais. A política garantista, preconizada por Ferrajoli (2006) é baseada no Direito Penal Mínimo, configurado por ser um direito repressivo, mas significativamente limitado às liberdades dos indivíduos diante do poder punitivo do Estado, diferentemente da corrente do maximalismo penal que prega um sistema de poder ilimitado, por ausência de limite à discricionariedade do legislador. Segundo Ferrajoli (2006), na política criminal de feição maximalista, a única convicção de que se tem é a de que nenhum culpado fique impune. De outro lado, na política criminal minimalista, a certeza é a de que nenhum inocente seja injustamente repreendido.

O mesmo autor assevera que uma política criminal consentânea com os modelos constitucionais contemporâneos, apoiada no respeito aos valores democraticamente escolhidos como ordenadores das ações dos agentes públicos e privados, tem como finalidade uma dupla função preventiva, qual seja, a prevenção geral dos delitos e a prevenção geral das penas arbitrárias ou desmedidas. Nesse cenário, a aplicação de uma política criminal garantista e minimalista é, sobretudo, a proteção do fraco contra o mais forte, em que os dois lados do sistema jurídico-penal justificam-se pela necessidade política da Justiça Penal tutelar os direitos fundamentais, que são bens ou valores que, em um Estado Democrático de Direito, devem ser preservados contra quaisquer ofensas, tanto oriundas de crimes como de penas.

Nessa linha de ideias, é forçoso reconhecer que os anseios da maioria nem sempre são consonantes com as necessidades políticas, apresentando-se, muitas vezes, em constante tensão com a democracia e com a maior participação popular nos assuntos da Justiça Penal. No entanto, como bem aduz Ferrajoli (2006), ainda que haja alguma impunidade, a adesão por juízes a uma política criminal minimalista e garantista afasta os desejos de vingança da opinião pública, da mídia e, até mesmo, de certas decisões legislativas. Este posicionamento também afasta a tendência catártica de diabolização dos acusados e de identificação do julgador com a vítima, assim como a supressão de direitos e garantias fundamentais dos delinquentes, como se estes fossem inimigos da sociedade. 
Reflexão imprescindível a ser realizada nesse ponto é justamente a de que a interpretação e a aplicação do Direito Penal estão associadas a um projeto político (GOMES, 2013). Isso significa dizer que juízes e tribunais, ao prolatarem alguma decisão, não apenas aplicam a letra da lei, mas, ao contrário, devem buscar a justiça que seja condizente com o sistema jurídico-penal, oferecendo uma resposta judicial baseada nos preceitos constitucionais, que veiculam a política do Estado, mesmo que, em certos momentos, possam exibir em suas decisões as deficiências do texto que interpretam. Assim, as sentenças judiciais são concebidas pela fusão de conceitos de dogmática jurídico-penal e de decisões políticocriminais. Em torno da dogmática jurídico-penal que é incorporada às decisões judiciais, existem finalidades e escolhas políticas referentes aos deveres e aos limites do Judiciário ao realizar o combate do crime e ao exercer o poder de punir do Estado.

Uma vez mais, ensina magistralmente Ferrajoli (2006) que as respostas judiciais ao crime devem ponderar as finalidades e proposições político-criminais que estão no quadro de valores que integram o consenso social positivado na Constituição, ainda que os sentimentos da maioria lhes exijam outra valoração. Assim sendo, os responsáveis pela interpretação e aplicação do Direito Penal devem estar orientados pelo objeto da política criminal, qual seja, o combate ao crime com o mínimo de violações de direitos. Entretanto, conforme aduz Hassamer (2008), a garantia de tais direitos acompanhada do combate à criminalidade é tensionada a todo instante, haja vista que fazer política com Direito Penal é sinônimo de um agir político com o mínimo de repressão e de sofrimento. Dessa sorte, uma política criminal efetiva nos dias atuais é aquela baseada na busca por sua própria superação e a procura de alternativas que sejam menos traumáticas aos direitos dos cidadãos. Afirma o mesmo autor que, "uma boa política social é a melhor forma de política criminal", sendo que a política criminal deve "não apenas responder mais apropriadamente aos nossos problemas, mas também deixar em paz os direitos fundamentais dos cidadãos", enfrentando "as ameaças de nosso tempo não com lesões aos direitos fundamentais, mas com medidas efetivas de proteção e segurança" (HASSEMER, 2008, p. 307, 308 e 309).

Concluindo, o Estado Democrático de Direito necessita imperiosamente de um movimento oposto ao de expansão do Direito Penal e as competências da Justiça Penal, em que sobrelevam os sentimentos de vingança apoiados na opinião pública e na mídia sensacionalista. Tal senso direciona uma correta compreensão de que uma democracia efetiva exige uma maior proteção dos direitos dos cidadãos e, de outro lado, um maior controle dos deveres do Estado. Somente dessa forma é que será possível atingir o equilíbrio entre a 
maximização da liberdade e a minimização do poder de punir do Estado. Nas palavras de Ferrajoli, a atividade punitiva do Estado, apoiada em uma política social maximalista, deve-se “graças à maximização das expectativas materiais e à correlativa expansão das obrigações públicas de satisfazê-las" (FERRAJOLI, 2006, p. 799).

\section{CONSIDERAÇÕES FINAIS}

No que se refere a tudo o que foi exposto neste trabalho, a conclusão primeira a que se chega, com apoio em Eugenio Zaffaroni, é que o discurso jurídico-penal dos dias atuais há muito perdeu sua legitimidade, tendo perdido mesmo a sua compatibilidade com o próprio Estado de Direito. Assim os sistemas penais "torcem e retorcem" em uma estrutura que cancela o próprio discurso jurídico-penal.

Em segundo lugar, pode-se concluir que o resgate da legitimidade do Direito Penal deve necessariamente passar por uma aproximação entre o plano normativo e a realidade, para que os diplomas normativos não sejam mera "letra morta" diante de uma crua e violenta realidade como é a brasileira.

Ademais, essa guinada em direção à legitimidade deve estar escorada em um viés jurídico-penal que propugne pelo equilíbrio, pois, como se viu, o Direito Penal Simbólico não é capaz de fornecer a segurança jurídica e a manutenção da ordem social através da decretação de um verdadeiro estado de guerra e da criminalização total da vida - que em nada resolve para o Direito Penal senão em mais uma forma de reprodução seletiva de violência em pretensas roupagens de Estado de Direito - e nem a total abolição do Direito Penal deve ser incentivada, já que é este um "mal necessário" à sociedade.

Isto posto, cabe ponderar em linha final que o Direito Penal não é a salvação para todos os problemas sociais, mas, infelizmente, encontra-se em verdadeiro e pernicioso processo de expansão, sendo compreendido, muitas vezes, erroneamente, como algo que serviria para combater a maior parte das misérias sociais, levando então à edição de inúmeras leis e a divulgação intensa do espetáculo da mídia em que crimes terríveis são postos no palco coletivo da catarse social e a violência é elogiada em detrimento do direito. Nisso importa 
afirmar, categoricamente, que se trata de um verdadeiro e lamentável retrocesso, uma vez que, como já se referiu, incorpora componentes autoritários às diversas leis esparsas aos diplomas legais penalistas, o que implica, indubitavelmente, em mais desigualdade, injustiça e exclusão da conhecida clientela do Sistema Penal.

Portanto, ao fim e ao cabo, mais uma vez deve-se reiterar que o resgate da legitimidade no contexto da aplicação do Direito Penal deve se imiscuir em um contexto de equilíbrio da retórica jurídico-penal, em que o Direito Penal Mínimo toma corpo num importante papel de reafirmação da liberdade e dos direitos e garantias do individuo frente a um Estado que muitas vezes é excessivo em seu poder. Somente assim é que se alcançará a paz e a estabilidade social, com uma mínima intervenção do sistema penal através do discurso jurídico-penal, que não seja somente em teoria, mas que, na prática, possa se arvorar como símbolo de que a sociedade é capaz de ditar níveis mínimos de convivência que garantam o estado de bem estar social, em que o Direito Penal seria apenas garante das relações sociais, e não "massa de manobra" e instrumento ativista para uma falsa segurança da sociedade.

\section{REFERÊNCIAS BILIOGRÁFICAS}

ANJOS, Fernando Vernice dos. Direito penal simbólico e finalidade da pena. Boletim do IBCCRIM, n. 171, fev. 2007. Disponível em: http:/ / www.ibccrim.org.br / novo/ boletim _artigo / 3369- Direito- penal- simbólico - e- sinalidade- da- pena >. Acesso em: 04 ago 2015.

BARATTA, Alessandro. Criminologia Crítica e Crítica do Direito Penal: Introdução à Sociologia do Direito Penal. 3 ed. Rio de Janeiro: Revan, 2002.

BATISTA, Nilo. Midia e sistema penal no capitalismo tardio. Discursos sediciosos: crime, direito e sociedade, Instituto Carioca de Criminologia. Rio de Janeiro: Revan, ano 7, n⿳⺈ 12 , 2002.

BATISTA, Nilo. Introdução crítica ao direito penal. Rio de Janeiro: Revan, 1996.

BATISTA, Vera Malaguti. O Medo na Cidade do Rio de Janeiro: dois tempos de uma história. Rio de Janeiro: Revan, 2003.

BIANCHINI, Alice; MOLINA, Antonio García-Pablos de; GOMES, Luiz Flávio. Direito penal: introdução e princípios fundamentais. 2. ed. rev., atual. eampl. São Paulo: RT, 2009. 
BUSTOS RAMIREZ, Juan; HORMAZÁBAL MALARÉE, Hernan. Leciones de derecho penal. Madrid: Trota, 1997.

BUSTOS RAMIREZ, Juan; HORMAZÁBAL MALARÉE, Hernan. Nuevo sistema de derecho penal. Madrid: Trotta, 2004.

CALLEGARI, André Luís; WERMUTH, Maiquel Ângelo Dezordi. Sistema penal e política criminal. Porto Alegre: Livraria do Advogado, 2010.

DIAS, Jorge de Figueiredo. Direito Penal: parte geral - questões fundamentais - a doutrina geral do crime. Coimbra: Coimbra Editora, 2004.

DURKHEIM, E. Da divisão do trabalho social. 2. ed. Trad. Eduardo Brandão. São Paulo: Martins Fontes, 1999.

FERRAJOLI, Luigi. Direito e razão: teoria do garantismo penal. Tradução de Ana Paula Zomer Sica, Fauzi Hassan Choukr, Juarez Tavares, Luiz Flávio Gomes. 3. ed. São Paulo: Revista dos Tribunais, 2010.

Direito e razão: teoria do garantismo penal. 2. ed. Vários tradutores. São Paulo: Revista dos Tribunais, 2006.

FRANCO, Alberto Silva. Novas tendências do direito penal. Boletim IBCCRIM. São Paulo, v.5, n.56 esp., p. 2, jul. 1997.

GOMES, Luiz Flávio; ALMEIDA, Débora de Souza de. Populismo penal midiático: caso mensalão, mídia disruptiva e direito penal crítico. São Paulo: Saraiva, 2013.

GOMES, Luiz Flávio. Principio da ofensividade no direito penal. São Paulo: Revista dos Tribunais, 2002.

GOMES, Luiz Flávio; BIANCHINI, Alice. O direito penal na era da globalização. 1. ed. São Paulo: Revista dos Tribunais, 2002.

GRECO, Rogério. Direito penal do equilíbrio: uma visão minimalista do direito penal. $5^{\mathrm{a}}$ ed. Niterói: Impetus, 2010.

HASSEMER, Winfried; MUÑOZ CONDE, Francisco. Introducción a la criminología y al Derecho Penal. Valencia: TirantloBlanch, 1989.

HASSEMER, W. Direito Penal: fundamentos, estrutura, política. Trad. Adriana Meirelles [et. al]. Porto Alegre: Sergio Antonio Fabris, 2008.

HOBBES, Thomas. De Cive: elementos filosóficos a respeito do cidadão. Trad. Ingeborg Soler. Petrópolis: Vozes, 1993.

LOPES JUNIOR, Aury. Processo penal, tempo e risco: quando a urgência atropela as garantias. In: Processo Penal: Leituras Constitucionais. Gilson Bonato (Org.). Rio de Janeiro: Lumen Juris, 2003 
MIRABETE, Julio Fabbrini. Execução penal. São Paulo: Atlas. 2000.

MUÑOZ CONDE, Francisco. De Nuevo Sobre el Derecho Penal del Enemigo. Buenos Aires: Hammurabi, 2005.

NEPOMOCENO, Alessandro. Além da lei: a face obscura da sentença penal. Rio de Janeiro: Revan, 2004.

NUCCI, Guilherme de Souza. Manual de processo e execução penal. São Paulo: Revista dos Tribunais, 2005.

QUEIROZ, Paulo. Sobre a função do juiz criminal na vigência de um direito penal simbólico. Boletim do IBCCRIM, n. 74, jan. 1999. Disponível em: <http://www.ibccrim.org.br/novo/boletim_artigo/1064-Sobre-a-funcao-do-juiz-criminal-navigencia-de-um-direito-penal-simbolico>. Acesso em: 31 jul 2015.

ROXIN, Claus. Derecho penal - parte general. Madrid: Editorial Civitas, 1997.

SANTIAGO, Mir Puig. Direito penal: fundamentos e teoria do delito. Trad. Claudia Viana Gacia, José Carlos Nobre Porciúncula Neto. São Paulo: RT, 2007.

SANTOS, Juarez Cirino dos. Direito penal: parte geral. 4. ed. Florianópolis: Conceito Editorial, 2010.

SILVA SÁNCHEZ, Jesús-María. A expansão do direito penal: aspectos da política criminal nas sociedades pós-industriais. Tradução Luiz Otavio de Oliveira Rocha - São Paulo: Editora Revista dos Tribunais, 2002. - (Série as ciências criminais no século XXI; v. 11).

SILVESTRONI, Mariano H. Teoria constitucional del delito. Buenos Aires: Editores del Puerto, 2004.

THOMPSON, Augusto. Quem são os criminosos? - O crime e o criminoso: entes políticos. $2^{\mathrm{a}}$ ed. Rio de Janeiro: Lúmen Júris, 2007.

ZAFFARONI, Eugenio Raul. Em busca das penas perdidas: a perda da legitimidade do sistema penal. 3. ed. trad. Vânia Romano Pedrosa, Amir Lopez da Conceição. Rio de Janeiro: Revan, 1991.

ZAFFARONI, Eugenio Raúl. O inimigo no direito penal. Trad: Sérgio Lamarão. 2. ed. Rio de Janeiro: Revan, 2007. 